\title{
ANTESEDEN KEPUASAN DALAM MEMBENTUK LOYALITAS PELANGGAN
}

\author{
Yohana Angel Chrestina'), Marjam Desma Rahadhini²), Untung Sriwidodo ${ }^{3)}$ \\ ${ }^{1,2,3)}$ Fakultas Ekonomi Universitas Slamet Riyadi Surakarta \\ ${ }^{1)}$ yohana.angel.c@gmail.com, ${ }^{2}$ m_rahadhini@yahoo.com, ${ }^{3)}$ untung_sriwidodo@yahoo.com
}

\begin{abstract}
Abstrak:Cokelat memberikan banyak manfaat untuk kesehatan apabila dikonsumsi secukupnya, seperti mengurangi stres, menurunkan tekanan darah, meningkatkan sirkulasi darah, mengurangi resiko kanker. Sehingga olahan cokelat mempunyai peluang untuk dijadikan sebagai usaha bidang kuliner. Beragam menu rasa minuman disediakan oleh Franchise Cokelat Klasik, untuk memenuhi kepuasan pecinta minuman cokelat. Tujuan penelitian ini untuk menganalisis anteseden kepuasan (keragaman menu, kepercayaan, dan nilai pelanggan) dalam membentuk loyalitas pelanggan. Pengumpulan data menggunakan data primer dan sekunder. Metode pengambilan sampel menggunakan non-probability sampling dengan metode purposive sampling sebanyak 140 responden. Uji validitas dan reliabilitas menggunakan confirmatory factor analisis (CFA) dan cronbach's alpha. Metode analisis data menggunakan Structural Equation Modelling (SEM). Temuan penelitian diperoleh ada pengaruh keragaman menu, nilai pelanggan terhadap kepuasan, tidak ada pengaruh kepercayaan terhadap kepuasan pelanggan, ada pengaruh kepuasan terhadap loyalitas, ada pengaruh keragaman menu terhadap loyalitas, tidak ada pengaruh nilai pelanggan terhadap loyalitas, kepuasan memediasi pengaruh keragaman menu dan kepercayaan terhadap loyalitas pelanggan, kepuasan tidak memediasi pengaruh nilai pelanggan terhadap loyalitas. Saran kepada Franchise Cokelat Klasik Solo agar memperhatikan keragaman menu, menjaga kepercayaan dan nilai pelanggan sehingga dapat mendorong konsumen untuk membeli ulang, merekomendasikan pada orang lain dan menjadi loyal.
\end{abstract}

Kata kunci: keragaman menu, kepercayaan, nilai pelanggan, kepuasan, loyalitas pelanggan

\begin{abstract}
Chocolate provides various health benefits when consumed sufficiently, such as reducing stress, lowering blood pressure, improving blood circulation and reducing the risk of cancer. Therefore, processed chocolate has the opportunity to be a culinary product. To satisfy the wants of chocolate drink lovers, different drink flavours are provided by Chocolate Classic Franchise. The purpose of this study is to analyze the antecedents of satisfaction (menu diversity, trust, and customer value) in the formation of customer loyalty. Primary and secondary data were used. The sampling method is non-probability sampling with purposive sampling of 140 respondents. The Validity and reliability employed confirmatory factor analysis (CFA) and cronbach's alpha, respectively. Furthermore, the data analysis method used Structural Equation Modeling (SEM). This study concluded that there are influences of the diversity of the menu and the customers'value on their satisfaction, there is no effect of trust on customer satisfaction, there is influence of satisfaction on loyalty, there is influence of the diversity of the menu on the loyalty, there is no influence of the value of customer on loyalty, satisfaction mediates the effect of the diversity of the menu and confidence customer loyalty, satisfaction does not mediate the effect of customer value on loyalty. Finally, this study proposes an advice for Chocolate Classical Solo Franchise to pay attention to the diversity of the menu, to keep the trust and customer value to encourage consumers to repurchase, recommend to others and become loyal.
\end{abstract}

Keywords: diversity of the menu, trust, customer value, satisfaction, customer loyalty

\section{PENDAHULUAN}

Perkembangan selera pelanggan dalam mengkonsumsi makanan dan minuman menunjukkan bahwa perilaku konsumen sangatlah dinamis. Hal ini direspon oleh Franchise Cokelat Klasik yang menyediakan minuman menggunakan bahan dasar coklat yang diolah dengan berbagai ragam rasa, memberikan kualitas yang baik, dan kepercayaan pada pelanggan. Produk yang ditawarkan dapat merupakan strategi untuk memuaskan pelanggan dan mengikuti perkembangan selera pelanggan agar melakukan pembelian secara terus-menerus. Konsumen yang bersikap positif terhadap suatu produk disertai komitmen untuk membeli ulang dan merekomendasikan kepada orang lain adalah konsumen yang loyal. Konsumen yang loyal merupakan aset bagi perusahaan 
karena akan menginfokan hal-hal yang positif tentang produk kepada orang lain. Inilah yang menjadi kekuatan bagi perusahaan untuk terus memperbaiki kualitas produk.

Menu yang beragam dan variatif perlu diperhatikan agar konsumen tetap setia membeliproduk. Konsumenmelakukan pilihan pada produk diinginkan (Qin dan Prybutok, 2010). Hal ini karena konsumen memiliki selera yang berbeda-beda. Keragaman menu menjadi alternatif dalam mengkonsumsi pada saat yang hal yang lain juga dipertimbangkan. Kepercayaan pelanggan juga menjadi pertimbangan dalam mengkonsumsi produk. Kepercayaan adalah salah satu dimensi dari relationship marketing untuk menentukan sejauh mana yang dirasakan suatu pihak mengenai integritas dan janji yang ditawarkan pihak lain. Kepercayaan konsumen (consumer beliefs) adalah semua pengetahuan yang dimiliki oleh konsumen dan semua kesimpulan yang dibuat konsumen tentang objek, atribut dan manfaatnya (Mowen \& Minor, 2002). Nilai pelanggan adalah perbandingan antara keuntungan yang diperoleh pelanggan dengan biaya pengorbanan yang dikeluarkan (McDougall \& Levesque, 2000). Terciptanya kepuasan pelanggan merupakan salah satu indikator keberhasilan usaha. Kotler menyatakan, "Kepuasan pelanggan adalah tanggapan pelanggan terhadap evaluasi ketidaksesuaian yang dirasakan antara harapan yang sebelumnya dengan kinerja produk yang dirasakan" (Kotler dan Keller, 2009).

Perumusan masalah penelitian ini adalah: 1) apakah ada pengaruh keragaman menu, kepercayaan, dan nilai pelanggan terhadap kepuasan pada Franchise Cokelat Klasik Surakarta; 2) apakah ada pengaruh keragaman menu, kepercayaan, dan nilai pelanggan terhadap loyalitas pada Franchise Cokelat Klasik Surakarta; 5) apakah kepuasan memediasi pengaruh keragaman menu, kepercayaan, dan nilai pelanggan terhadap loyalitas pada Franchise Cokelat Klasik Surakarta.

\section{TINJAUAN PUSTAKA}

\section{Keragaman Menu}

Keragaman produk merupakan daya tarik bagi konsumen terutama dapat memberikan alternatif pilihan yang lebih bervariasi. Alternatif pilihan yang lebih bervariasi bagi konsumen dapat mendorong kepuasan konsumen (Botti \& Iyengar, 2006). Keragaman menu merupakan faktor yang penting untuk dapat memperluas target pasar dan memenuhi keinginan konsumen yang berbeda (Qin \& Prybutok, 2010). Bermacam-macam produk yang disediakan akan memudahkan konsumen dalam memilih dan membeli berbagai macam produk yang sesuai selera dan keinginan.

Franchise Cokelat Klasik menyediakan produk yang cukup banyak dan beragam dalam produk minuman ice/hot chocolate sehingga konsumen dapat memilih produk yang sesuai selera. Produk yang beragam dapat memberikan dorongan dan pilihan bagi konsumen untuk membeli produk yang memenuhi selera. Penyediaan keragaman produk yang baik tidak hanya akan membuat konsumen setia, tetapi juga dapat mempengaruhi kepuasan saat membeli dan mengkosumsinya.

\section{Kepercayaan}

Kepercayaan konsumen (consumer beliefs) adalah semua pengetahuan yang dimiliki konsumen dan semua kesimpulan yang dibuat konsumen tentang objek, atribut, dan manfaatnya, yaitu: (Mowen dan Minor, 2002)

1. Kepercayaan atribut-objek (objectattribute beliefs)

Kepercayaan atribut-objek adalah pengetahuan tentang sebuah obyek yang memiliki atribut khusus. Kepercayaan atribut-objek menghubungkan antara atribut dengan objek, seperti: seseorang, barang atau jasa.

2. Kepercayaan manfaat-attribute (attributebenefit beliefs)

Seseorang mencari produk yang akan menyelesaikan masalah dan memenuhi kebutuhan, seperti produk dan jasa.

3. Kepercayaan manfaat-objek (objectbenefit beliefs)

Kepercayaan yang dibentuk dengan menghubungkan objek dan manfaatnya. Kepercayaan manfaat merupakan persepsi konsumen tentang seberapa jauh produk, orang atau jasa tertentu yang akan memberikan manfaat tertentu. 


\section{Nilai Pelanggan}

Nilai pelanggan adalah perbandingan keuntungan yang diperoleh pelanggan dengan pengorbanan yang dikeluarkan (McDougall \& Levesque, 2000). Nilai bukan berarti hanya manfaat fungsional dari sebuah obyek, tetapi keseluruhan rangkaian dari proses penyampaian kepada pelanggan sampai pelayanan setelah penjualan, merupakan nilai yang dapat dinikmati oleh pelanggan. Menurut Tjiptono (2011), terdapat 4 aspek utama dimensi nilai pelanggan yaitu:

1. Emotional value (nilai emosional)

Kemampuan yang berkaitan dengan perasaan atau emosional sebagai akibat penggunaan produk.

2. Social value (nilai sosial)

Kemampuan yang berkaitan dengan kesan sosial yang baik dalam masyarakat.

3. Quality/performance value (nilai kualitas)

Kemampuan produk yang dinilai memiliki kinerja dan fungsi yang bagus.

4. Price value (nilai harga)

Kemampuan produk yang diperoleh dari efisiensi harga.

\section{Kepuasan}

Kepuasan adalah perasaan senang atau kecewa seseorang yang muncul setelah membandingkan kinerja produk yang dipikirkan terhadap kinerja yang diharapkan (Kotler dan Keller, 2009). Terciptanya kepuasan konsumen merupakan salah satu indikator keberhasilan usaha. Kotler menyatakan, "Kepuasan pelanggan adalah tanggapan konsumen terhadap evaluasi ketidaksesuaian yang dirasakan antara harapan yang sebelumnya dengan kinerja produk yang dirasakan" (Kotler dan Keller, 2009).

Perusahaanyangberfokuspadapelanggan, kepuasan pelanggan adalah sasaran dan sekaligus alat pemasaran. Kepuasan pelanggan adalah hasil akumulasi dari konsumen atau pelanggan dalam menggunakan produk atau jasa (Irawan, 2008). Konsumen yang merasa puas akan suatu produk akan selalu menggunakan produk tersebut secara terus menerus. Kepuasan konsumen merupakan faktor penting bagi perusahaan karena dapat meningkatkan volume penjualan. Dalam menentukan tingkat kepuasan konsumen, terdapat lima faktor utama yang harus diperhatikan oleh perusahaan, antara lain: kualitas produk, kualitas pelayanan, emosional, harga dan biaya (Irawan, 2008).

\section{Loyalitas Pelanggan}

Loyalitas pelanggan adalah situasi dimana konsumen bersikap positif terhadap produk atau produsen (penyedia jasa/produk) dan disertai pola pembelian ulang yang konsisten (Tjiptono, 2011). Loyalitas konsumen sebagai kerangka berpikir konsumen yang memiliki sikap yang disukai terhadap sebuah perusahaan, berkomitmen untuk membeli lagi produk perusahaan serta merekomendasikan produk tersebut (Parasuraman et al dalam Akbar dan Parvez, 2009).

Loyalitas merupakan suatu sikap positif konsumen terhadap suatu produk maupun pada perusahaan itu sendiri yang disertai dengan komitmen untuk membeli produk dan merekomendasikannya pada pihak lain. Griffin (2005) mengemukakan terdapat beberapa atribut dalam mengukur loyalitas konsumen, yaitu: melakukan pembelian berulang dan konsisten, merekomendasikan kepada orang lain, membeli produk dan jasa lain dengan produsen yang sama, menunjukkan kekebalan daya tarik produk sejenis dari pesaing, membeli atau mengkonsumsi produk yang dijual dalam waktu dekat.

\section{METODE PENELITIAN}

Penelitian ini merupakan penelitian survei yang dilakukan pada Franchise Cokelat Klasik Surakarta. Sumber data adalah data primer dan data sekunder. Jenis data adalah data kualitatif dan kuantitatif. Populasi target adalah konsumen yang pernah melakukan pembelian dan berniat loyal di Franchise Cokelat Klasik Surakarta. Metode pengambilan sampel menggunakan purposive sampling, sampel penelitian sebanyak 140 responden. Pengumpulan data menggunakan kuesioner. Metode analisis data menggunakan analisis Structural Equation Modelling (SEM) program Amos. Pengujian validitas digunakan Confirmatory Factor Analysis (CFA) dan pengujian reliabilitas menggunakan Cronbach 's Alpha. Dalam analisis SEM harus dipenuhi asumsi sebagai berikut: 
Tabel 1. Goodness of Fit Index

\begin{tabular}{|c|c|c|}
\hline No & Goodness Of Fix Index & Cut Of Value \\
\hline 1 & Chi-Square & Diharapkan Kecil \\
\hline 2 & Signifikansi & $\geq 0,05$ \\
\hline 3 & RMSEA & $\leq 0,08$ \\
\hline 4 & GFI & $\geq 0,90$ \\
\hline 5 & AGFI & $\leq 0,90$ \\
\hline 6 & CMIN/ DF & $\leq 2,00$ \\
\hline 7 & TLI & $\geq 0,95$ \\
\hline 8 & CFI & $\geq 0,94$ \\
\hline
\end{tabular}

\section{HASIL DAN PEMBAHASAN}

\section{Karakteristik Responden}

Karakteristik responden penelitian yang paling dominan diperoleh: 1) usia 15-20 tahun $37,14 \%$; 2) wanita $68,58 \%$; 3) tingkat pendidikan Perguruan Tinggi 37,86\%; 4) sebagai pelajar/mahasiswa $35,72 \%$; 5) frekuensi berkunjung lebih dari 4 kali $35,71 \%$; 6) berasal dari Kota Solo 67,86\%; 7) pendapatan 1-3 juta per bulan $35,71 \%$.

\section{Hasil Uji Instrumen}

Pengujian validitas dengan menggunakan confirmatory factor analysis adalah valid, karena besarnya nilai factor loading > 0,50 sehingga instrumen penelitian layak digunakan. Sedangkan pengujian reliabilitas mengenai variabel keragaman menu 0,702 ; kepercayaan 0,854 ; nilai pelanggan 0,805 ; kepuasan 0,734 dan loyalitas 0,722 menunjukkan reliabel karena nilai cronbach's alpha $>0,60$.

\section{Pengujian Goodness of Fit}

Pengujian kriteria Goodness of Fit digunakan untuk melihat apakah model sudah memenuhi asumsi yang disyaratkan untuk dianalisis dengan SEM. Hasil uji GFI ditunjukkan dalam tabel berikut:

Tabel 2. Pengujian Goodness Of Fit (GFI)

\begin{tabular}{llrl}
\hline \multicolumn{1}{c}{ GFI Index } & \multicolumn{1}{c}{ Cut-Off Value } & Hasil Uji & Evaluasi Model \\
\hline Chi-Square & $\chi^{2}$ mendekati nol & 494,207 & - \\
Probabilitas & $\geq 0,05$ & 0,00 & Poor fit \\
GFI & $\geq 0,90$ & 0,81 & Marjinal \\
AGFI & $\geq 0,90$ & 0,77 & Poor fit \\
TLI & $\geq 0,95$ & 0,84 & Marjinal \\
CFI & $\geq 0,95$ & 0,85 & Marjinal \\
RMSEA & $\geq 0,08$ & 0,05 & Marjinal \\
CMIN/DF & $\leq 2,0$ & 1,62 & Good fit \\
\hline \multicolumn{5}{c}{ Sumber: Data primer diolah, 2017} &
\end{tabular}

Nilai CMIN/DF menunjukkan bahwa model good fit sesuai dengan kriteria yang disyaratkan, meskipun nilai GFI, TLI, CFI, dan RMSEA berada dalam kondisi marjinal serta nilai probabilitas dan AGFI berada dalam kondisi poor fit, menunjukkan model layak.
Ini berarti model cukup fit dan layak untuk digunakan.

\section{Pengujian Model Struktural}

Pengujian model struktural untuk pada analisis SEM, diperoleh hasil sebagai berikut: 


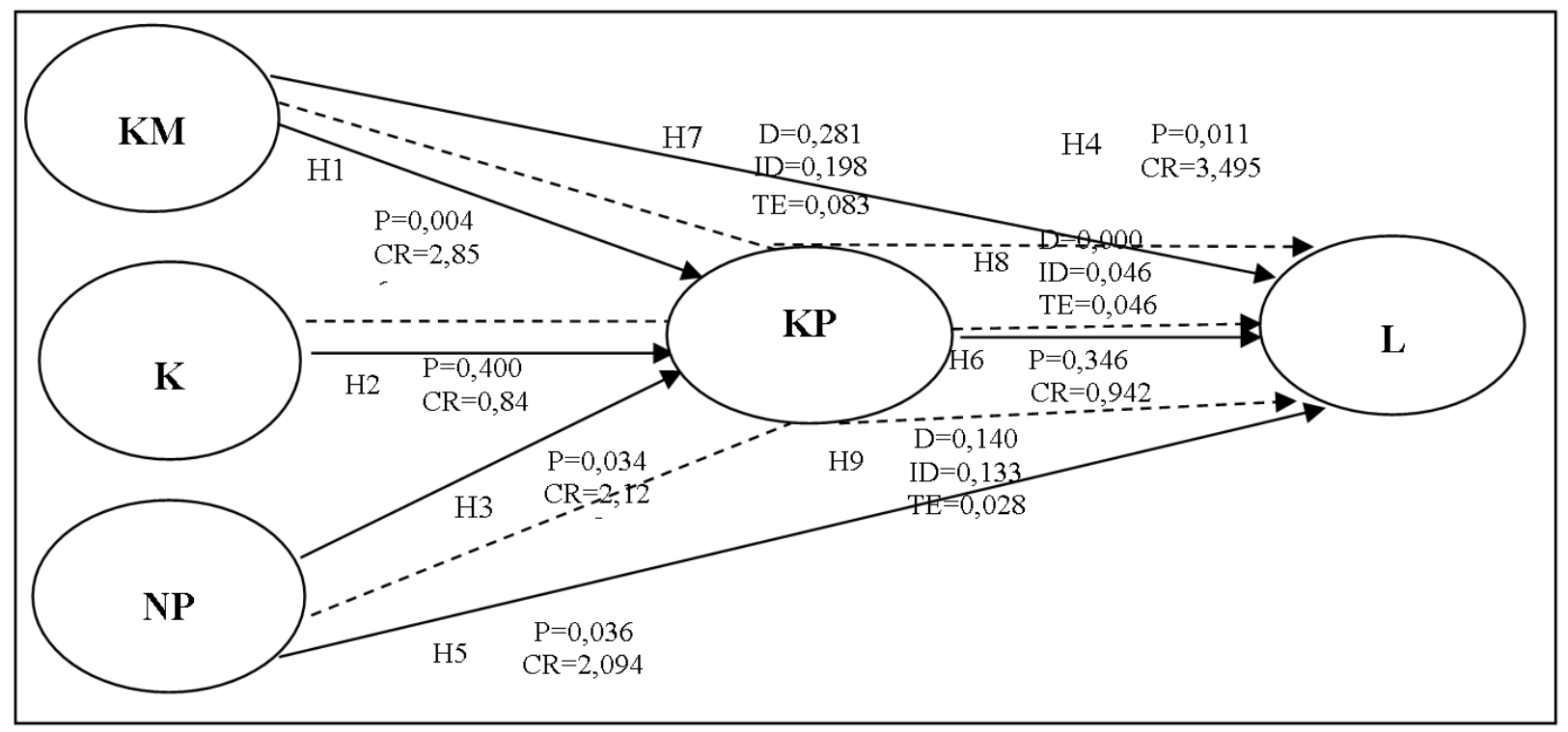

Gambar 1. Model Struktural

\section{Pengujian Hipotesis}

Pengujian hipotesis didasarkan dengan menganalisis nilai critical ratio (CR) dan nilai probability (p). Hasil analisis SEM dibandingkan dengan nilai statistik yang disyaratkan, yaitu nilai estimate $>1.96$ untuk nilai $\mathrm{CR}<0,05$. Adapun hasil regression weights ditunjukkan dalam tabel berikut:

Tabel 3. Hasil Regression Weights

\begin{tabular}{|c|c|c|c|c|c|c|c|}
\hline & & & Estimate & S.E. & C.R & $\mathrm{P}$ & Label \\
\hline $\mathrm{KP}$ & $<--$ & KM & 0,274 & 0,096 & 2,856 & 0,004 & Signifikan \\
\hline KP & $<---$ & $\mathrm{K}$ & 0,080 & 0,095 & 0,841 & 0,400 & Tidak signifikan \\
\hline KP & $<---$ & NP & 0,216 & 0,102 & 2,125 & 0,034 & Signifikan \\
\hline $\mathrm{L}$ & $<---$ & $\mathrm{KP}$ & 0,522 & 0,150 & 3,495 & *** & Signifikan \\
\hline $\mathrm{L}$ & $<--$ & KM & 0,203 & 0,097 & 2,094 & 0,036 & Signifikan \\
\hline $\mathrm{L}$ & $<--$ & NP & 0,089 & 0,094 & 0,942 & 0,346 & Tidak signifikan \\
\hline
\end{tabular}

Dari hasil pengujian hipotesis, dapat dijelaskan sebagai berikut:

1. Terdapat pengaruh keragaman menu terhadap kepuasan pelanggan, diperoleh nilai CR 2,856 > 1,96 dan nilai p 0,004 $<0,004$ sehingga hipotesis 1 terbukti. Hasil penelitian ini mendukung penelitian Uswatun dan Harti (2015) yang menunjukkan bahwa keragaman menu berpengaruh terhadap kepuasan pelanggan. Keragaman menu dengan menyajikan berbagai macam variasi olahan cokelat, dan cita rasa yang khas serta dikemas secara menarik mampu memunculkan kepuasan bagi pelanggan Franchise Cokelat Klasik Surakarta.

2. Terdapat pengaruh kepercayaan terhadap kepuasan pelanggan, diperoleh nilai $\mathrm{CR}$ $0,841<1,96$ dan nilai $\mathrm{p} 0,400>0,05$ sehingga hipotesis 2 tidak terbukti. Hasil penelitian tidak sesuai dengan penelitian Rakhmat dan Firdaus (2016) yang menunjukkan bahwa kepercayaan berpengaruh positif dan signifikan terhadap kepuasan pelanggan. Ini berarti pemilik seharusnya memberikan pemahaman tentang produk secara benar, supaya pelanggan dapat mengerti bahwa produk yang baik dan berkualitas merupakan produk yang dapat memberikan kepercayaan, sehingga dapat meningkatkan kepuasan pelanggan.

3. Terdapat pengaruh nilai pelanggan terhadap kepuasan pelanggan, diperoleh nilai CR 2,125 > 1,96 dan nilai $\mathrm{p} 0,034$ $<0,05$ sehingga hipotesis 3 terbukti. Hasil penelitian ini didukung penelitian yang dilakukan oleh Mardikawati dan Farida (2013) yang menyatakan bahwa pelanggan akan membentuk harapan berdasarkan nilai dan berperilaku sesuai dengan harapannya, dan pelanggan juga 
akan memperhitungkan dan mengevaluasi penawaran yang memberikan nilai (value) yang tinggi baginya.

4. Terdapat pengaruh kepuasan pelanggan terhadap loyalitas, diperolehnilaiCR3,945 $>1,96$ dan nilai $\mathrm{p} 0,001<0,05$ sehingga hipotesis 4 terbukti. Hasil penelitian ini mendukung penelitian Hasanah dan Harti (2015) yang menyatakan bahwa kepuasan merupakan faktor kunci bagi konsumen dalam melakukan pembelian ulang, yang mana hal ini merupakan hal yang penting untuk meningkatkan volume penjualan. Konsumen yang merasa puas terhadap suatu produk akan selalu menggunakan produk tersebut secara terus menerus.

5. Terdapat pengaruh keragaman menu terhadap loyalitas, diperoleh nilai CR 2,094> 1,96 dan nilai p 0,036 < 0,05 sehingga hipotesis 5 terbukti. Hasil penelitian ini mendukung penelitian Hasanah dan Harti (2015) yang menunjukkan bahwa keragaman menu berpengaruh signifikan terhadap kepuasan pelanggan. Keragaman menu yang disediakan akan menimbulkan sikap positif konsumen terhadap suatu produk maupun pada perusahaan itu sendiri yang disertai dengan komitmen untuk membeli produk tersebut dan merekomendasikannya pada pihak lain.

6. Terdapat pengaruh nilai pelanggan terhadap loyalitas, diperoleh nilai $\mathrm{CR}$ $0,942<1,96$ dan nilai p $0,346>0,05$ sehingga hipotesis 6 tidak terbukti. Hasil yang didapat tidak sesuai dengan penelitian Mardikawati dan Farida (2013) yang menunjukkan bahwa nilai pelanggan berpengaruh signifikan terhadap loyalitas. Hal ini seharusnya memberikan pemahaman kepada pelanggan bahwa nilai pelanggan dapat meningkatkan loyalitas, dimana sejumlah biaya yang dikeluarkan oleh konsumen dipergunakan untuk mendapatkan, menggunakan dan mengevaluasi produk.

7. Kepuasan pelanggan memediasi pengaruh keragaman menu terhadap loyalitas, diperoleh nilai pengaruh langsung (Direct) keragaman menu terhadap loyalitas 0,281 ; nilai pengaruh tidak langsung (Indirect) 0,198; dan nilai total effect (TE) 0,083; didapatkan TE >
(D x ID) atau 0,083 > 0,055; sehingga hipotesis 7 terbukti. Hasil penelitian ini sesuai dengan penelitian Mardikawati dan Farida (2013) yang menunjukkan bahwa keragaman menu terhadap loyalitas dan kepuasan pelanggan terhadap loyalitas mempunyai pengaruh yang signifikan. Hal ini menunjukkan seharusnya pemilik memberikan variasi produk yang semakin beragam sesuai dengan selera pelanggan, supaya pelanggan merasa lebih puas dan semakin banyak orang yang tertarik untuk melakukan pembelian.

8. Kepuasan memediasi pengaruh kepercayaan terhadap loyalitas, diperoleh nilai pengaruh langsung (Direct) kepercayaan terhadap loyalitas 0,000 ; nilai pengaruh tidak langsung (Indirect) 0,046; dan nilai total effect (TE) 0,046; didapatkan TE > (D x ID) atau 0,046> 0,000 ; sehingga hipotesis 8 terbukti. Hasil penelitian tidak sesuai dengan penelitian Hidayat Deddy dan Muhammad Riza (2016) yang menunjukkan bahwa kepercayaan berpengaruh positif dan signifikan terhadap kepuasan pelanggan dan loyalitas pelanggan. Implikasinya seharusnya pemilik memberikan pemahaman kepada pelanggan bahwa kepercayaan pada produk yang berkualitas dan baik dapat meningkatkan kepuasan pelanggan.

9. Kepuasan memediasi pengaruh nilai pelanggan terhadap loyalitas, diperoleh nilai pengaruh langsung (Direct) nilai pelanggan terhadap loyalitas 0,104 ; nilai pengaruh tidak langsung (Indirect) 0,133; dan nilai total effect (TE) 0,028 ; didapatkan TE $>$ (D x ID) atau 0,028 $<0,781$ sehingga hipotesis 9 tidak terbukti. Hasil penelitian ini tidak sesuai dengan penelitian Mardikawati dan Farida (2013) yang menyatakan bahwa variabel kepuasan pelanggan berperan memediasi kepercayaan terhadap loyalitas. Hal ini menunjukkan pemilik seharusnya memberikan pemahaman kepada pelanggan bahwa nilai pelanggan dapat meningkatkan loyalitas pelanggan melalui kepuasan yang diberikan, dimana sejumlah biaya yang dikeluarkan konsumen digunakan untuk mendapatkan dan mengevaluasi produk. 


\section{KESIMPULAN}

Kesimpulan dalam penelitian ini bahwa keragaman menu dan nilai pelanggan faktor yang penting untuk menciptakan kepuasan pelanggan. Demikian juga pelanggan yang memiliki kesan yang baik terhadap kualitas produk, harga, dan pelayanan karyawan di Franchise Cokelat Klasik Surakarta, akan membuat pelanggan merasa puas. Pemilik seharusnya menyediakan produk yang berkualitas dan sesuai dengan harapan pelanggan supaya pelanggan mendapatkan kepuasan dari produk yang dikonsumsi. Semakin tinggi kepuasan yang dirasakan pelanggan semakin kuat mendorong pelanggan untuk melakukan pembelian ulang. Semakin baik kualitas produk yang dihasilkan dan variasi rasa di Franchise Cokelat Klasik Surakarta, maka pelanggan semakin loyal. Nilai pelanggan yang diperoleh pelanggan cukup untuk menimbulkan rasa keingintahuan dan kesan yang baik terhadap produk sehingga pelanggan tidak merasa ragu untuk membeli.

Kepuasan memediasi pengaruh keragaman menu terhadap loyalitas, karena pelanggan yang loyal akan merekomendasikan kepada orang lain. Pemilik dapat meningkatkan kepercayaan pelanggan dengan meningkatkan kinerja karyawan, menjaga kualitas produk dan kepuasan akan produk yang diperoleh pelanggannya. Peningkatan pelayanan dan kinerja karyawan, supaya pelanggan merasa puas saat melakukan pembelian dan memiliki keinginan untuk melakukan pembelian ulang.

Saran yang dapat diberikan pada pemilik Franchise Cokelat Klasik Surakarta, hendaknya memperhatikan keragaman menu yang disediakan seperti variasi rasa, dan mencoba menciptakan rasa yang baru sesuai dengan permintaan dan selera pelanggan. Pemilik hendaknya juga memperhatikan kepercayaan dan nilai pelanggan terutama ketika ramai pengunjung sehingga konsumen tidak terlalu lama menunggu untuk dilayani. Kepuasan perlu diperhatikan, karena kepuasan pelanggan dapat diraih melalui peningkatan kualitas pelayanan, penentuan harga yang kompetitif, penanganan keluhan konsumen yang intensif, dan melakukan survei kepuasan konsumen secara berkesinambungan dan terprogram.

\section{DAFTAR PUSTAKA}

Akbar, Muhammad Muzahid dan Noorjahan Parvez. 2009. "Impact of Service, Quality, Trust and Customer Satisfaction on Customer Loyalty. ABAC. Vol.29, No.1 (January-April). p 24-38.

Arifin, Zainal. 2008. Metodologi Penelitian Pendidikan. Lentera Cendikia. Surabaya.

Botti, S. \& Iyengar, S.S. 2006. "The Dark Side of Choice: When Choice Impairs Social Welfare". Journal of Public Policy \& Marketing, 25(1). p 24-38.

Ferdinand, Augusty. 2014. Structural Equation Modeling dalam Penelitian Manajemen. BP UNDIP. Semarang.

Ghozali, Imam. 2013. Aplikasi Analisis Multivariat dengan Program IBM SPSS 21. Edisi 7. Badan Penerbit Universitas Diponegoro. Semarang.

Griffin, Jill. 2005. Customer Loyalty: Menumbuhkan dan Mempertahankan Kesetiaan Pelangga. (Alih Bahasa: Dwi Kartini Yahya). Edisi Revisi, Erlangga. Jakarta.

Hasanah, Uswatun dan Harti. 2015. "Pengaruh Keragaman Menu, Harga dan Kualitas Pelayanan terhadap Loyalitas Pelanggan dengan Kepuasan sebagai Variabel Intervening pada Waroeng "SS" (Spesial Sambal) Surabaya". Jurnal Mahasiswa Teknologi Pendidikan. Vol. 1, No.1. p.1-9.

Hidayat, Deddy Rakhmat dan Muhammad Riza Firdaus. 2016. "Analisis Pengaruh Kualitas Layanan, Harga, Kepercayaan, Citra Perusahaan dan Kepuasan Pelanggan terhadap Loyalitas Pelanggan (Studi pada Pelanggan Telkom Speedy di Palangka Raya)". Jurnal 
Wawasan Manajemen. Vol. 2, No. 3. p. 237-249.

Irawan, Handi. 2008. Sepuluh Prinsip Kepuasan Pelanggan. Elex Media Komputindo. Jakarta.

Kotler, Philip dan Lane Kevin Keller. 2009. Manajemen Pemasaran. Jilid 1. Edisi keempat (terjemahan). Erlangga. Jakarta.

Mardikawati, Woro dan Naili Farida. 2013. "Pengaruh Nilai Pelanggan dan Kualitas Pelayanan terhadap Loyalitas Pelanggan, melalui Kepuasan Pelanggan pada Pelanggan Bus Efisiensi (Studi PO Efisiensi Jurusan Yogyakarta-Cilacap)". Jurnal Administrasi Bisnis. Vol.2, No.1.p. 64-75.

McDougall and Levesque. 2000. "Costumer Satisfaction with Service: Putting Perceived Value into The Equation". Journal of Services Marketing, Vol.14, No.5. p 392-410.

Mowen, John dan Michael Minor. 2002. Perilaku Konsumen. Erlangga. Jakarta.

Rofianah, Patricia Dhiana Paramita dan Aziz Fathoni. 2016. "Pengaruh Product Quality, Service Quality dan Customer Preceived Value Terhadap Customer Loyalty dengan Mediasi Trust Pelanggan pada Mini Market Alfamart Boja Kendal". Journal of Management. Vol. 2, No. 2.

Tjiptono, Fandy. 2011. Prinsip-prinsip Total Quality Service. Andi Offset. Yogyakarta.

Qin, H and Prybutok, V.R. 2010. "Service Quality, Customer Satisfaction, and Behavioral Intention in Fast Food Restaurant". International Journal of Quality and Services Sciences, Vol. 1, p 78-95. 